\title{
Sputum induction with inhaled mannitol in children
}

\author{
To the Editor:
}

Mannitol is used as an indirect challenge test to assess airway hyperresponsiveness in asthmatic adults and children as young as 4 years old [1-4]. Recently, it has been tested with success in adults as a sputum inducer $[5,6]$. In children, induced sputum is usually obtained by hypertonic saline solution (HSS) and has several indications, such as sample obtaining in infectious diseases [7], monitoring severe asthma [8] and defining asthma phenotypes [9].

To our knowledge there have been no studies about the use of mannitol to obtain induced sputum in children. The aim of this study was to assess the feasibility and safety of the mannitol challenge test to obtain induced sputum in young children. This pilot study is part of a project to study bronchial responsiveness and inflammation in asthmatic and nonasthmatic skier children.

This is a cross-sectional, observational and descriptive study. Healthy and asthmatic children (7-13 years old) were randomly selected from a ski club (Ordino Arcalís Ski Club, Ordino Arcalís, Andorra). The study was approved by the Ethics Committee of Nostra Senyora de Meritxell Hospital (Escaldes-Engordany, Andorra), and written informed consent from parents as well as authorisations from the ski club were obtained for participation in the study. Inclusion criteria for asthmatic children were diagnosis of bronchial asthma, regardless of the severity, and absence of asthma symptoms with no need for short-acting $\beta_{2}$-agonists or oral corticosteroids during the previous month.

The protocol study included: determination of the exhaled nitric oxide fraction with a NIOX MINO device (Aerocrine, Solna, Sweden); skin-prick testing (ALK-Abelló allergen extracts; ALK, Round Rock, TX, USA) for the common respiratory allergens; and a bronchoprovocation test and sputum induction with inhaled mannitol.

The mannitol challenge test was performed by a progressive protocol [2]. Dry powder mannitol (Osmohale; Aldo-Unión, Esplugues de Llobregat, Spain) was inhaled in step-wise doses $(0,5,10,20,40$, $80,160,160,160 \mathrm{mg}$ ). Measurements of forced expiratory volume in $1 \mathrm{~s}$ (FEV1) were taken pre-dose and 1 min post-dose, with the highest value for FEV1 being recorded. A positive response was considered to be when FEV1 fell by $\geqslant 15 \%$ or when FEV1 fell by $\geqslant 10 \%$ between consecutive doses.

To obtain the induced sputum, the child was encouraged to cough up sputum into a sterile container after the inhalation of each mannitol dose.

Sputum examination was performed as previously described [10], following the method of PizZICHINI et al. [11]. In brief, sputum was separated from contaminating saliva and weighed. Samples had to weigh $\geqslant 50 \mathrm{mg}$ to be accepted as valid. The aliquot was then dispersed with four volumes of freshly prepared dithiothreitol solution. The mixture was vortexed, and after being rocked for $15 \mathrm{~min}$, four volumes of Dulbecco's PBS were added. The suspension was then filtered through 48-mm nylon gauze (Millipore Corporate Headquarters, Billerica, MA, USA) and centrifuged at $314 \times g$ for $10 \mathrm{~min}$. This resulted in the formation of a cell pellet and supernatant solution. The supernatant was stored at $-80^{\circ} \mathrm{C}$ for analysis of inflammatory factors. The proportion of salivary squamous cells was noted and cell viability was determined using the trypan blue exclusion method. The specimens were considered adequate if squamous cells represented $<20 \%$ and viable cells $\geqslant 60 \%$ of the total cell population. Cytospin cell preparations were made using a cytocentrifuge. The cytospin slides were stained with May-Grünwald-Giemsa to determine the differential cell count, made by counting 400 cells per slide. Sputum eosinophilia was established when the percentage of eosinophils was $\geqslant 2.5 \%$ [12].

We studied seven asthmatic and 10 healthy children (table 1). All but one of the asthmatic children were found to be atopic. Three patients had intermittent episodic asthma and four had persistent asthma, well controlled with inhaled steroids in two of the patients and with omalizumab in the other two patients.

A successful sputum induction was obtained in 13 of the 17 children (76.5\%), allowing an adequate study of sputum cellularity (table 1). We did not obtain good sputum samples in three healthy and one asthmatic child: two healthy boys with a viability of $53 \%$ and $54 \%$, one healthy girl with a $0 \%$ viability and one asthmatic boy with a viability of $66 \%$ but $25 \%$ squamous cell contamination. 
TABLE 1 Mannitol challenge and induced sputum results

\begin{tabular}{lcc} 
& Asthmatic & Healthy \\
\hline Subjects & 7 & 10 \\
Females & 4 & 3 \\
Age years median (range) & $9(7-13)$ & $10(8-13)$ \\
FeNo ppb & $15(9-40)$ & $15(13-30)$ \\
Positive mannitol tests & 4 & 3 \\
PD15 mg & $304(118-469)$ & $421(207-565)$ \\
RDR & $0.03(0.01-0.07)$ & $0.01(0.01-0.04)$ \\
Adequate sputum samples & $\mathbf{6}$ & 7 \\
Sputum viability \% & 6 & $75(63-84)$ \\
Sputum weight g & $74(68-87)$ & $0.26(0.2-0.38)$ \\
Sputum total cell counts $\cdot \mathbf{g}^{-1} \times \mathbf{1 0}^{\mathbf{6}}$ & $0.24(0.10-0.29)$ & $1.3(0.6-1.53)$ \\
Sputum eosinophilia & $2.1(1.06-7.80)$ & 1 \\
Sputum eosinophils \% & 5 & $0(0-0.5)$ \\
\hline
\end{tabular}

Data are presented as $\mathrm{n}$ or median (interquartile range), unless otherwise stated. FeNO: exhaled nitric oxide fraction; ppb: parts per billion; PD15: provocative dose causing a $15 \%$ fall in forced expiratory volume in $1 \mathrm{~s}$ (FEV1); RDR: response dose ratio (final $\%$ fall $F E V_{1} /$ cumulative dose). " : squamous cells $<20 \%$ and viable cells $\geqslant 60 \%$.

The challenge test was well tolerated and adverse events were mild in all patients with no need to stop the test in any case; cough $(n=17)$, aerophagia $(n=3)$, vomiting $(n=2)$, sore throat $(n=7)$, bad taste in mouth $(\mathrm{n}=10)$. The median duration of the mannitol test in all the children was 55 (range 50-59) min.

In this preliminary study, we report that sputum can be successfully induced in children aged 7-13 years with inhaled mannitol. The success rate of this technique to obtain a good sputum sample was somewhat higher than our previous results using HSS: 62\% in 108 children [10].

In a previous adult study, induced sputum was obtained from $89 \%$ of subjects during a saline challenge and $76 \%$ of subjects during the mannitol challenge. There was a lower total cell count in mannitol versus hypertonic saline-induced sputum. However, sputum eosinophils and neutrophils were not significantly different and using mannitol, a higher proportion of subjects was classified as having eosinophilic asthma [5].

The most frequent adverse event in our study was cough, with all children coughing during the test in comparison with only $29 \%$ of asthmatic children in our previously published study with HSS [10]. However, this is an intrinsic characteristic of the mannitol effect, which may be useful to induce sputum and the cough was not important enough to stop the test.

Otherwise, the bronchoprovocation test was positive in four of the seven asthmatic children and in three of the 10 healthy children. Further studies are required in relation to the specificity and sensitivity of the test in skier children.

In summary, in spite of the small sample size, the success rate in obtaining a good-quality sputum sample was quite high. According to our results, the mannitol challenge test can be used in young children to perform a bronchoprovocation test and sputum induction at the same time in order to study both hyperresponsiveness and inflammation.

- @ERSpublications

Acceptable induced sputum samples can be obtained in healthy and asthmatic children using the mannitol challenge test http://ow.ly/KSd2M

Gerardo Vizmanos-Lamotte, Elisa Canturri Gispert ${ }^{2}$, Víctor Núñez Eroles ${ }^{2}$, Mireia Martínez Abelló ${ }^{2}$, Joan Martínez Benazet ${ }^{2}$ and Antonio Moreno-Galdó ${ }^{3,4}$

${ }^{1}$ Paediatrics Dept, Hospital Nostra Senyora de Meritxell, SAAS, Escaldes-Engordany, Andorra. ${ }^{2}$ Pulmonology Dept, Hospital Nostra Senyora de Meritxell, SAAS, Escaldes-Engordany, Andorra. ${ }^{3}$ Paediatric Pulmonology Unit, Hospital Universitari Vall d'Hebron, Barcelona, Spain. ${ }^{4}$ Dept de Pediatria, Obstetrícia i Ginecologia i Medicina Preventiva, Universitat Autònoma de Barcelona, Barcelona, Spain.

Correspondence: Gerardo Vizmanos-Lamotte, Carretera Coll d'Ordino s/n, Edifici Terratorta, bloc A, 1er 2a, AD 300 Ordino, Andorra. E-mail: gerardovizmanos@gmail.com

Received: Nov 132014 | Accepted after revision: March 15 2015 | First published online: May 142015

Support statement: This study was supported by the Aldo-Unión (Esplugues de Llobregat, Spain). 


\section{References}

1 Koskela HO, Hyvärinen L, Brannan JD, et al. Responsiveness to three bronchial provocation tests in patients with asthma. Chest 2003; 124: 2171-2177.

2 Brannan JD, Anderson SD, Perry CP, et al. The safety and efficacy of inhaled dry powder mannitol as a bronchial provocation test for airway hyperresponsiveness: a phase 3 comparison study with hypertonic (4.5\%) saline. Respir Res 2005; 6: 144.

3 Kersten ET, Driessen JM, van der Berg JD, et al. Mannitol and exercise challenge tests in asthmatic children. Pediatr Pulmonol 2009; 44: 655-661.

4 Alblooshi AS, Simpson SJ, Stick SM, et al. The safety and feasibility of the inhaled mannitol challenge test in young children. Eur Respir J 2013; 42: 1420-1423.

5 Wood LG, Powell H, Gibson PG. Mannitol challenge for assessment of airway responsiveness, airway inflammation and inflammatory phenotype in asthma. Clin Exp Allergy 2010; 40: 232-241.

6 Anderson SD, Brannan JD. Bronchial provocation testing and collection of sputum with inhaled mannitol. Clin Exp Allergy 2010; 40: 193-196.

7 Zar HJ, Tannenbaum E, Hanslo D, et al. Sputum induction as a diagnostic tool for community-acquired pneumonia in infants and young children from a high HIV prevalence area. Pediatr Pulmonol 2003; 36: 58-62.

8 Fleming L, Wilson $\mathrm{N}$, Regamey $\mathrm{N}$, et al. Use of sputum eosinophil counts to guide management in children with severe asthma. Thorax 2012; 67: 193-198.

9 Fleming L, Tsartsali L, Wilson N, et al. Sputum inflammatory phenotypes are not stable in children with asthma. Thorax 2012; 67: 675-681.

10 Vizmanos-Lamotte G, Moreno-Galdó A, Muñoz X, et al. Induced sputum cell count and cytokine profile in atopic and non-atopic children with asthma. Pediatr Pulmonol 2013; 48: 1062-1069.

11 Pizzichini E, Pizzichini M, Efthimiadis A, et al. Indices of airway inflammation in induced sputum: reproducibility and validity of cell and fluid-phase measurements. Am J Respir Crit Care Med 1996; 154: 308-317.

12 Gibson PG, Grootendor DC, Henry RL, et al. Sputum induction in children. Eur Respir J 2002; 20: Suppl. 37, $44 s-46 s$.

\section{Successful treatment of antineutrophil cytoplasmic antibody-associated bronchiectasis with immunosuppressive therapy}

To the Editor:

The underlying mechanisms of bronchiectasis are poorly understood and the cause remains unknown in half of the patients [1]. Whether bronchiectasis is the direct consequence of pathogen aggression or of an abnormal immune response remains unresolved [2-4]. We report here the first case of a patient with bronchiectasis improved by an immunosuppressive regimen.

In 2010, a 27-year-old male nonsmoker was referred by his oncologist to our respiratory department (Hôpital Foch, Suresnes, France) for recurrent haemoptysis associated with anaemia at $90 \mathrm{~g} \cdot \mathrm{L}^{-1}$ and abnormal chest computed tomography (CT) scan.

He first sought medical advice in our hospital in 2008 for a testicular stage I nonseminomatous germ cell tumour. Despite the PT2 stage of the tumour (with vascular emboli) and the pure carcinoma histology, he declined to receive adjuvant chemotherapy and chose an active surveillance policy. This implied repeated CT scans and follow-up visits. The cancer was in complete remission in 2010.

He reported several episodes of cough and spitting, all considered as minor infections, even before the orchiectomy, but pulmonary symptoms continued to worsen. He had no other symptoms, was in very good shape otherwise, with a performance status of 0 , a weight of $80 \mathrm{~kg}$ and height of $180 \mathrm{~cm}$.

While the 2008 chest CT scan only exhibited bi-basilar micronodules, the chest CT scan performed in 2010 revealed bi-apical ground-glass opacities with a crazy paving pattern with interlobular septal 